\title{
Index System of University Teachers Based on Multi-objective and AHP Evaluation
}

\author{
Dan SONG \\ School of Information Science and Engineering, Central South University, Hunan Changsha 410083, China \\ Department of Information Management, Hunan University of Finance and Economics, Hunan Changsha \\ 410205, China.
}

Sha FU, Feng YAN

Department of Information Management, Hunan University of Finance and Economics, Hunan Changsha 410205, China

\begin{abstract}
Based on the Pareto inferior sorting and analytic hierarchy process (AHP), a kind of multiobjective evaluation index system for university teachers' evaluation is constructed. The system introduces in inferior sorting from the theory of multiple objective, using analytic hierarchy process in the system of the second and third floors index, and using an inferior sorting method in a layer of index (subgoal layer) to choose winners, which can ensure that the object does not inferior to others. In the empirical analysis, compared with the traditional weighted method, multi-objective evaluation index system can be more objectively review object for comprehensive evaluation.
\end{abstract}

KEYWORD: multi-objective optimization; evaluation; analytic hierarchy process

\section{INTRODUCTION}

Teacher evaluation will be defined as an organizational capability by American scholar. Through a comprehensive judgment of the behavior and ability of teachers to determine the appointment and continuing appointment[1]. In recent years, governments have developed science teacher evaluation system to ensure the quality of education and improve the quality of teachers[2-3].

When building various types of evaluation system, more and more scholars have used a variety of modern, intelligent evaluation methods to carry out. Analytic Hierarchy Process (AHP) has systemic, simple, flexible features, and is suitable for integrated use with other intelligent evaluation method. For example, the combination of the AHP and fuzzy method is applied to high-tech research evaluation[4]; Comprehensive Fuzzy-AHP to build a multi-level comprehensive evaluation method[5]; Grey incidence analysis on influence factors of online auditing performance assessment[6]; Health state assessment of water-based system for Dongjiang basin based on rough set theory and set pair analysis[7]. In the study of teacher evaluation system, scholars have made some useful exploration: LIU et al have combined gray theory and AHP to apply to evaluation system of university teachers[8], and WANG et al have constructed a new teacher evaluation model with the idea put forward fuzzy mathematics and gray system theory into analytic hierarchy process[9]; From the internal structure of human capital, members contribution of the research team have evaluated[10].
In summary, the majority of scholars often use weighted summation manner of the level indicators of different dimensions to build tiered evaluation system. They fail to take account of its heterostructure of different quality indicators, less use of Pareto ranking approach to select appraised. This paper introduces the intelligent multi-objective optimization methods in the theory of non-dominated sorting based multiobjective theory (Pareto ordering) and Analytic Hierarchy Process (AHP) to establish evaluation index system, and the practice is applied to teacher evaluation.

\section{MULTI-OBJECTIVE EVALUATION INDEX SYSTEM OF UNIVERSITY TEACHERS}

The university teachers' professional ability is divided into basic quality $\left(\mathrm{G}_{1}\right)$, the education teaching ability $\left(G_{2}\right)$, innovation ability of scientific research $\left(G_{3}\right)$. Aiming at the three teachers' professional ability, the system formulates corresponding subgoals, and constitute the subgoal layer of a multiple objective evaluation index system of university teachers. According to professional features and requirements the system builds the rule layer of the secondary and tertiary indicators. Specific college teachers layered evaluation index is shown in table 1 .

The evaluation index system of university teachers think that the primary index as the subgoals. If their subgoals are computed by simple sum, or a weighted sum, the way does not effectively show different properties of each subgoal. If they are evaluated 
completely by the expert group in the meeting, because of various subjective factors, it is difficult to gain a objective and fair evaluation. Using Pareto sorting method of multi-objective optimization in subgoal level, comprehensive ranking selection of evaluation object, the system can achieve a more scientific to teacher's value judgment and evaluation.
The overall goal of the system as a multi-objective optimization problem, one objective function for each sub-goal. Under the subgoal level (secondary and below index) the system use AHP method and the 1-9 scale method to conduct quantitative research. After obtaining each individual sub-goals score (objective function value) by AHP, the system use Pareto sort of thought to select better teachers.

Table 1. Evaluation index system of university teacher

\begin{tabular}{|c|c|c|c|}
\hline Total goal & Subgoal layer & Rule layer one & Rule layer two \\
\hline \multirow{23}{*}{$\begin{array}{l}\text { Evaluation } \\
\text { of university } \\
\text { teacher }\end{array}$} & \multirow{6}{*}{$\begin{array}{l}\text { Basic quality } \\
\left(\mathrm{G}_{1}\right)\end{array}$} & \multirow{3}{*}{$\begin{array}{l}\text { Basic performance and } \\
\text { ability }\left(I_{1}\right)\end{array}$} & The performance of politics and ethics $\left(\mathrm{I}_{11}\right)$ \\
\hline & & & The annual assessment $\left(\mathrm{I}_{12}\right)$ \\
\hline & & & The level of foreign language and computer $\left(\mathrm{I}_{13}\right)$ \\
\hline & & \multirow{3}{*}{$\begin{array}{l}\text { Background of education } \\
\text { and qualification }\left(\mathrm{I}_{2}\right)\end{array}$} & Diploma and degree, the professional technical position $\left(\mathrm{I}_{21}\right)$ \\
\hline & & & To adapt to the needs of professional teaching $\left(\mathrm{I}_{22}\right)$ \\
\hline & & & Continuing education $\left(\mathrm{I}_{23}\right)$ \\
\hline & \multirow{9}{*}{$\begin{array}{l}\text { Education } \\
\text { teaching ability } \\
\left(\mathrm{G}_{2}\right)\end{array}$} & \multirow{3}{*}{ Classroom teaching $\left(\mathrm{I}_{3}\right)$} & Classroom management $\left(\mathrm{I}_{31}\right)$ \\
\hline & & & Preparing the lessons and homework assessment $\left(\mathrm{I}_{32}\right)$ \\
\hline & & & The task of teaching and teaching work $\left(\mathrm{I}_{33}\right)$ \\
\hline & & \multirow{3}{*}{$\begin{array}{l}\text { Teaching method and effect } \\
\left(\mathrm{I}_{4}\right)\end{array}$} & Language expression, using modern teaching means and so on $\left(\mathrm{I}_{41}\right)$ \\
\hline & & & The teaching evaluation from students $\left(\mathrm{I}_{42}\right)$ \\
\hline & & & Peer evaluation $\left(\mathrm{I}_{43}\right)$ \\
\hline & & \multirow{3}{*}{$\begin{array}{l}\text { Research and reform of } \\
\text { education }\left(I_{5}\right)\end{array}$} & Host and participate in all levels of the educational reform project $\left(\mathrm{I}_{51}\right)$ \\
\hline & & & The educational reform papers $\left(\mathrm{I}_{52}\right)$ \\
\hline & & & Practical teaching and the educational reform practice $\left(\mathrm{I}_{53}\right)$ \\
\hline & \multirow{8}{*}{$\begin{array}{l}\text { Innovation } \\
\text { ability of } \\
\text { scientific } \\
\text { research }\left(\mathrm{G}_{3}\right)\end{array}$} & \multirow{3}{*}{$\begin{array}{l}\text { Project of scientific } \\
\text { research }\left(\mathrm{I}_{6}\right)\end{array}$} & The work of scientific research $\left(\mathrm{I}_{61}\right)$ \\
\hline & & & Government sponsored research projects $\left(\mathrm{I}_{62}\right)$ \\
\hline & & & Lateral academic research projects $\left(\mathrm{I}_{63}\right)$ \\
\hline & & \multirow{3}{*}{$\begin{array}{l}\text { Paper and special } \\
\text { chopsticks }\left(\mathrm{I}_{7}\right)\end{array}$} & Journal articles $\left(\mathrm{I}_{71}\right)$ \\
\hline & & & Papers in conference and newspaper $\left(\mathrm{I}_{72}\right)$ \\
\hline & & & The special chopsticks $\left(\mathrm{I}_{73}\right)$ \\
\hline & & \multirow{2}{*}{ Achievement and honor $\left(I_{8}\right)$} & Research awards $\left(\mathrm{I}_{81}\right)$ \\
\hline & & & Policy recommendations, transformation of achievements, Patent $\left(\mathrm{I}_{82}\right)$ \\
\hline
\end{tabular}

\section{EMPIRICAL STUDY OF MULTI-OBJECTIVE EVALUATION SYSTEM OF UNIVERSITY TEACHERS}

\subsection{The use of AHP methods for the two and three layers of index weight setting}

\subsubsection{Constructing judgment matrix}

Invited a number of experts for the score of each level index (the promotion of technical titles of university teachers, for example), the experts, according to relative importance of the same level index, in accordance with requirements of AHP, use 1-9 scaling method to finish pair comparison of all index and judge their importance. Finally, the recovery of expert questionnaire are transformed to the constructing judgment matrix.
An expert on the scientific research aspects of the $\mathrm{I}_{6}$ to the $\mathrm{I}_{8}$ index score as an example:

Table 2. Judgment matrix for level $2\left(\mathrm{I}_{6}, \mathrm{I}_{7}, \mathrm{I}_{8}\right)$

\begin{tabular}{|l|l|l|l|}
\hline level 2 & $\mathrm{I}_{6}$ & $\mathrm{I}_{7}$ & $\mathrm{I}_{8}$ \\
\hline Project of scientific research $\left(\mathrm{I}_{6}\right)$ & 1 & $1 / 2$ & $3 / 2$ \\
\hline Paper and special chopsticks $\left(\mathrm{I}_{7}\right)$ & 2 & 1 & 3 \\
\hline Achievement and honor $\left(\mathrm{I}_{8}\right)$ & $2 / 3$ & $1 / 3$ & 1 \\
\hline
\end{tabular}

\subsubsection{Calculating the weight and consistency test}

(1)Calculating $M i$ by multiplying the elements of each row of judgment matrix

$$
\begin{aligned}
& M_{i}=\prod_{j=1}^{n} a_{i j} \quad i=1,2, \cdots, n \\
& M=[0.75,6,0.2222]
\end{aligned}
$$


(2)Vector $\quad \bar{W}=\left[\bar{W}_{1}, \bar{W}_{2}, \cdots, \bar{W}_{n}\right]^{T} \quad$ normalization, obtaining feature vector (that is, the index weight value)

$$
W_{i}=\frac{\bar{w}_{i}}{\sum_{j=1}^{n} \bar{w}_{j}}, \bar{W}_{i}=\sqrt[n]{M_{i}}
$$

$W=[0.2727,0.5455,0.1818], G_{3}=(0.2727,0.5455$, $0.1818)$

(3)Calculating the maximum characteristic root $\lambda_{\max }$ of judgment matrix

$$
\lambda_{\max }=\sum_{i=1}^{n} \frac{(A W)_{i}}{n W_{i}}=\frac{1}{3} \sum_{1}^{3} \frac{(A W)_{i}}{n W_{i}}=3
$$

(4)Consistency test

$$
C I=\frac{\lambda_{\max }-n}{n-1}=\frac{3-3}{3-1}=0 \quad, \quad C R=C I / \mathrm{RI}=0<0.1 .
$$

Therefore, the judgement matrix have satisfactory consistency.

\subsubsection{Calculating the index weight of each layer}

Through the statistics and calculation in accordance with the above method, we can get the specific weight of all index on layer 2 and layer 3 , and integrate experts' results to get the final weight values:

$G_{I}=(0.35,0.65), I_{1}=(0.23,0.59,0.18), I_{2}=(0.60$, $0.13,0.27)$

$G_{2}=(0.23, \quad 0.17,0.60), \quad I_{3}=\left(\begin{array}{lll}0.55, & 0.19, & 0.26\end{array}\right)$, $I_{4}=(0.11,0.31,0.58), I_{5}=(0.57,0.33,0.10)$

$G_{3}=(0.28, \quad 0.51, \quad 0.21), \quad I_{6}=(0.16, \quad 0.69, \quad 0.15)$, $I_{7}=(0.43,0.13,0.44), I_{8}=(0.75,0.25)$

\subsection{Using the Pareto sorting into title promotion}

Sub object layer has a total of three indicators, in the layer using non dominated sorting method (a multiobjective method) to select the better.
Multi-objective optimization problems including objective function, decision variables and the domain, its general structure is as follows:

$$
\begin{array}{r}
\min \left\{f(X)=\left[f_{1}(X), \cdots, f_{i}(X), \cdots, f_{m}(X)\right]\right\}, \\
X=\left(X_{1}, \cdots, X_{j}, \cdots, X_{n}\right), \\
X_{j \min } \leq X_{j} \leq X_{j \max }, j=1,2, \cdots, m .
\end{array}
$$

Among them: $X \in R^{n}$ for a vector with $n$ decision variables, it constitutes the decision space, $X_{j m i n}$ and $X_{j \max }$ as its upper and lower boundaries. $f(X) \in R^{m}$ for the vector with $m$ objective function, it constitutes the objective space.

In this paper, the basic definition of multi-objective optimization is commonly used in the following:

Pareto dominance: solution $X_{1}$ Pareto dominates $\mathrm{X}_{2}\left(\mathrm{X}_{1} \prec \mathrm{X}_{2}\right)$, if and only if at the same time

$$
\begin{gathered}
f_{i}\left(X_{1}\right) \leq f_{i}\left(X_{2}\right), \forall i=1,2, \cdots, n ; \\
f_{i}\left(X_{1}\right)<f_{i}\left(X_{2}\right), \exists\{i=1,2, \cdots, n\} .
\end{gathered}
$$

Pareto optimal: if $X$ is Pareto optimal when and only when

$$
\neg \exists X_{i}: X_{i} \prec X .
$$

Pareto non inferior solution set: vector set that constituted by all the Pareto solutions.

$$
P_{S}=\left\{X \mid \neg \exists X_{i} \prec X\right\} .
$$

\subsection{Empirical analysis}

Extraction ten teachers (T1-T10) with the same professional title from the evaluation database, the pass rate is set to $40 \%$, and the results obtained by Pareto non dominated sorting are shown in Table 3.

Table 3. The score of level 3 index for evaluation teachers

\begin{tabular}{|l|l|l|l|l|l|l|l|l|l|l|l|l|l|l|l|l|l|l|l|l|l|l|l|}
\hline & $I_{11}$ & $I_{12}$ & $I_{13}$ & $I_{21}$ & $I_{22}$ & $I_{23}$ & $I_{31}$ & $I_{32}$ & $I_{33}$ & $I_{41}$ & $I_{42}$ & $I_{43}$ & $I_{51}$ & $I_{52}$ & $I_{53}$ & $I_{61}$ & $I_{62}$ & $I_{63}$ & $I_{71}$ & $I_{72}$ & $I_{73}$ & $I_{81}$ & $I_{82}$ \\
\hline $\mathrm{T} 1$ & 42 & 45 & 80 & 90 & 83 & 60 & 60 & 62 & 61 & 60 & 70 & 68 & 65 & 60 & 65 & 80 & 75 & 75 & 78 & 85 & 78 & 70 & 75 \\
\hline T2 & 81 & 88 & 80 & 79 & 86 & 78 & 95 & 86 & 92 & 88 & 90 & 91 & 95 & 90 & 90 & 60 & 65 & 36 & 67 & 66 & 50 & 35 & 36 \\
\hline T3 & 85 & 80 & 75 & 65 & 75 & 86 & 88 & 83 & 81 & 82 & 81 & 83 & 55 & 59 & 65 & 72 & 71 & 30 & 70 & 65 & 53 & 60 & 25 \\
\hline T4 & 95 & 75 & 80 & 68 & 73 & 65 & 75 & 82 & 78 & 75 & 76 & 78 & 40 & 50 & 60 & 55 & 65 & 30 & 65 & 60 & 55 & 75 & 60 \\
\hline T5 & 86 & 75 & 70 & 75 & 86 & 78 & 70 & 76 & 80 & 83 & 82 & 81 & 32 & 20 & 55 & 50 & 60 & 25 & 70 & 75 & 20 & 48 & 45 \\
\hline T6 & 77 & 70 & 50 & 95 & 65 & 73 & 83 & 80 & 81 & 75 & 72 & 73 & 36 & 38 & 58 & 60 & 65 & 30 & 45 & 35 & 40 & 30 & 36 \\
\hline T7 & 68 & 80 & 60 & 80 & 75 & 85 & 75 & 75 & 82 & 65 & 60 & 78 & 75 & 67 & 60 & 75 & 70 & 42 & 56 & 69 & 10 & 48 & 25 \\
\hline T8 & 88 & 90 & 75 & 85 & 80 & 83 & 82 & 71 & 75 & 70 & 74 & 80 & 67 & 77 & 70 & 80 & 82 & 30 & 75 & 63 & 68 & 60 & 60 \\
\hline T9 & 85 & 75 & 70 & 75 & 65 & 89 & 80 & 72 & 77 & 82 & 83 & 85 & 76 & 80 & 75 & 88 & 87 & 90 & 86 & 74 & 75 & 80 & 65 \\
\hline T10 & 78 & 75 & 60 & 88 & 75 & 85 & 81 & 75 & 73 & 74 & 76 & 80 & 80 & 70 & 76 & 78 & 78 & 83 & 75 & 86 & 65 & 72 & 60 \\
\hline
\end{tabular}

System can get index weight of layer $2\left(\mathrm{I}_{1}-\mathrm{I}_{8}\right)$ by weighted-calculation of index of layer 3 . Further, through weighted-calculation of index of layer 2 the system can get the sub goal scoring (G1-G3), as shown in table 4: 
Table 4. The index score of level 2 and level1 for evaluation teachers

\begin{tabular}{|l|l|l|l|l|l|l|l|l|l|l|l|}
\hline & $I_{I}$ & $I_{2}$ & $I_{3}$ & $I_{4}$ & $I_{5}$ & $I_{6}$ & $I_{7}$ & $I_{8}$ & $G_{I}$ & $G_{2}$ & $G_{3}$ \\
\hline T1 & 51 & 81 & 61 & 68 & 63 & 76 & 79 & 71 & 70 & 63 & 76 \\
\hline T2 & 85 & 80 & 93 & 90 & 93 & 60 & 59 & 35 & 81 & 92 & 54 \\
\hline T3 & 80 & 72 & 85 & 82 & 57 & 65 & 62 & 51 & 75 & 68 & 61 \\
\hline T4 & 81 & 68 & 77 & 77 & 45 & 58 & 60 & 71 & 72 & 58 & 62 \\
\hline T5 & 77 & 77 & 74 & 82 & 30 & 53 & 49 & 47 & 77 & 49 & 50 \\
\hline T6 & 68 & 85 & 82 & 73 & 39 & 59 & 42 & 32 & 79 & 55 & 44 \\
\hline T7 & 74 & 81 & 77 & 71 & 71 & 67 & 37 & 42 & 78 & 72 & 47 \\
\hline T8 & 87 & 84 & 78 & 77 & 71 & 74 & 70 & 60 & 85 & 73 & 69 \\
\hline T9 & 76 & 77 & 78 & 84 & 77 & 88 & 80 & 76 & 77 & 78 & 81 \\
\hline T10 & 73 & 86 & 78 & 78 & 76 & 79 & 72 & 69 & 81 & 77 & 73 \\
\hline
\end{tabular}

The following graphical way to represent sub-goals of individual teacher from Table 4, as shown in Figure 1.

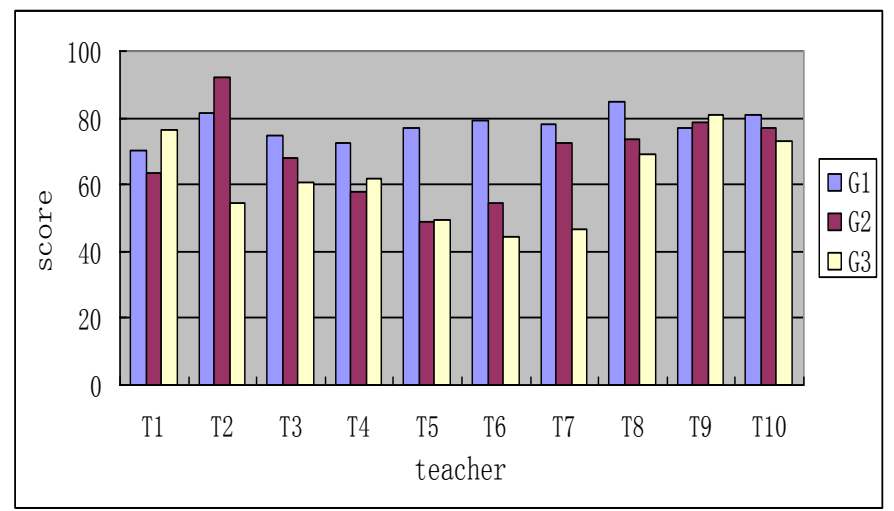

Figure 1. Sub-goal scores column chart of individual teachers

According to 3.2, Pareto non dominated sorting of individual teachers, the system can get the set of noninferior solutions for (T2, T8, T9, T10).

Calculating by using the traditional Weighted statistical methods for sub goal layer (with weight is $0.2,0.3,0.5)$, we can get the top four (T9, T10, T8, T1).

The main difference between two is that the former has selected T2, the latter has selected T1.

Analysis of the various sub-targets ranking in groups about T1: tenth place in basic quality $\left(\mathrm{G}_{1}\right)$, seventh place in the education teaching ability $\left(\mathrm{G}_{2}\right)$, second place in the innovation ability of scientific research $\left(G_{3}\right)$. For T2: second place of $G_{1}$, first place of $\mathrm{G}_{2}$, seventh place of $\mathrm{G}_{3}$. Learned from the comparison, $\mathrm{T} 2$ has excellent ranking of two sub goals, and T1 has two sub goals ranked poor. But the traditional method will select $\mathrm{T} 1$ teacher, and $\mathrm{T} 2$ will be eliminated.

\section{CONCLUSION}

By using simple summation or weighted sum of sub goals the traditional method can't show good performance of different nature of sub goals. This paper uses the Pareto non dominated sorting, and the first comparison occurred within each sub goal is the comparison of indexes of internal similar. Further, by using non dominated sorting in the global, the selected object is not inferior to other objects.

Therefore, based on the Pareto inferior sorting and AHP, this paper has constructed a kind of multiobjective evaluation index system for university teachers' evaluation. The empirical analysis shows that the method has certain advancement, which is worth further exploration and research in selection work.

\section{ACKNOWLEDGEMENTS}

This work was supported by the National Science \& Technology Pillar Program (grant code: 2012BAH08B01), the Scientific Research Fund of Hunan Provincial Education Department (grant code: 12B021, 13A010), the Teaching Reform Project of Ordinary University of Hunan Province (grant code: 20130551), the Scientific Research Fund of Hunan Financial and Economics University (grant code: K201302), and the Postdoctoral Science Foundation of Central South University.

\section{REFERENCES}

[1] Nolan J, Hoover L A. Teacher supervision and evaluation: the combination of theory and practice. Beijing: light industry press, 2007.

[2] Department for Education and Employment. Education Regulations 2001. London: DfES, 2001.

[3] Http://www.tda.gov.uk/upload/resources/pdf/s/standards_fra mework.pdf [EB/OL]. Framework of Professional Standards for Teachers in England, 2007.

[4] ZHANG Shou-hua, SUN Shu-dong. Evaluation of HighTech Research Project Based on Internal Fuzzy TOPSIS and AHP. Journal of Shanghai Jiaotong University, 2011, 01:134-138.

[5] PENG Dongli, HU Tian, GUO Yunkai. Evaluation of expansive soil slope stability based on Fuzzy-AHP method. Journal of Central South University (Science and Technology), 2014, 02:622-628.

[6] CHEN Wei, SMIELIAUSKAS Wally, LIU Sifeng. Grey incidence analysis on influence factors of online auditing performance assessment. Application Research of Computers, 2012, 02:435-437.

[7] HUANG Guoru, WU Chuanhao, XIANG Biwei. Health state assessment of water-based system for Dongjiang basin based on rough set theory and set pair analysis. Systems Engineering-Theory \& Practice, 2014, 05:1345-1351.

[8] LIU binghui. College Teacher Evaluation Based on the multi-level gray theory. Statistical Research, 2010, 06:10911.

[9] WANG Minggang, XU Hua. Construction Based GFAHP research assessment system of university teachers. Statistics and Decision. 2011, 17:169-171.

[10]ZHANG Lili, ZHAO Xinan. Contribution Evaluation and Analysis Method Based on Advantage Structure of Human Capital Inner Quality. Systems Engineering, 2013, 31(04): 72-77. 